\title{
Host-biting rate and susceptibility of some suspected vectors to Leishmania braziliensis
}

Morgana Michele Cavalcanti de Souza Leal Diniz ${ }^{1}$, Fredy Galvis Ovallos ${ }^{1 *}$, Claudia Maria de Castro Gomes², Cecilia de Oliveira Lavitschka ${ }^{3}$ and Eunice Aparecida Bianchi Galati ${ }^{4 *}$

\begin{abstract}
Background: American tegumentary leishmaniasis is a serious Brazilian public health problem. This diseases is attributed to seven species of Leishmania, however, the majority of cases are associated with Leishmania braziliensis. Some phlebotomine species have been implicated in the transmission of this parasite, nonetheless only Psychodopygus wellcomei has had its vectorial competence demonstrated. Thus this study sought to assess some parameters related to the vectorial capacity of anthropophilic species of sand fly occurring in São Paulo state: Pintomyia fischeri, Migonemyia migonei Nyssomyia intermedia, Nyssomyia whitmani, Expapillata firmatoi and Psychodopygus ayrozai, under laboratory conditions. These parameters were the duration of the gonotrophic cycle, proportion of females which feed on hamster, the rate of infection by L. braziliensis and the duration of the extrinsic incubation period.

Methods: The sandflies were collected in three regions of the São Paulo state: Greater São Paulo and the Mogi Guaçu and Iporanga municipalities. To assess the proportion of engorged females the insects were fed on hamsters to estimate the duration of the gonotrophic cycle. To estimate the susceptibility to infection of each species, their females were fed on hamsters infected with Leishmania braziliensis and dissected to ascertain the localization of the flagellates and estimate the extrinsic incubation period.
\end{abstract}

Results: Low hamster attractiveness to PS. ayrozai was observed. A high proportion of engorged females was observed when the hamster had its whole body exposed. The gonotrophic cycle ranged between three and eight days. Mg. migonei, Pi. fischeri, Ny. neivai, Ny. intermedia, Ny. whitmani and Ex.firmatoi presented susceptibility to infection by L. braziliensis. The highest infection rate (34.4\%) was observed for Ny. whitmani and the lowest for $\mathrm{Ny}$. intermedia (6.6\%). Mg. migonei presented late-stage infection forms on the fifth day after feeding, but in the other species these forms were observed as from the fourth day.

Conclusions: Our results, together with other parameters of their behavior under natural conditions, suggest the potential role of Ex. firmatoi as vector of this parasite and reinforce that of Mg. migonei, Pi. fischeri, Ny. neivai, $\mathrm{Ny}$. intermedia and Ny. whitmani in the areas in which they occur.

Keywords: Phlebotominae, Host biting rate, Vectorial capacity, Leishmania (Viannia) braziliensis, Vector

\footnotetext{
* Correspondence: galvisfregao@gmail.com; egalati@usp.br

${ }^{1}$ Postgraduate Program in Public Health, School of Public Health, University

of São Paulo - USP, São Paulo, SP, Brazil

${ }^{4}$ Department of Epidemiology, School of Public Health, University of

São Paulo - USP, São Paulo, SP, Brazil

Full list of author information is available at the end of the article
} 


\section{Background}

American tegumentary leishmaniasis (ATL) may be characterized as a complex of diseases caused by 14 species of the Leishmania genus that infect humans, some affecting the skin and others the skin and the mucous membranes [1-3]. It is a zoonosis involving a variety of reservoirs represented by wild animals, synanthropic and domestic animals, and vectors $[4,5]$. Its importance for public health is due to the damage it causes to the tissues, the psychosocial impact on the people affected, the disability adjusted life years lost (DALYs) in the populations [5] and its wide geographical distribution in the Central and South America, apart from Chile and Uruguay which have no recorded cases [6,7].

This disease has been attributed in Brazil to seven species of Leishmania: Leishmania (L.) amazonensis), L. (Viannia) braziliensis, L. (V.) guyanensis, L. (V.) lainsoni, L. (V.) shawi, $L$. (V.) naiffi and $L$. (V.) lindenbergi. The majority of cases are associated with $L$. braziliensis which presents the most widespread geographical distribution and is associated with cases of the mucocutaneous form. The wild rodents Oryzomys concolor, O. capito, O. nigripes, Akodon arviculoides, Proechyms sp. Rattus rattus and Rhipidomys leucodactylus and the opossum Didelphis marsupialis have been found as natural hosts of this parasite [8].

Although various phlebotomine species have been implicated in the transmission of L. braziliensis [2,8], only Psychodopygus wellcomei has had its vectorial competence demonstrated [9]. However, on the basis of such criteria as anthropophily, high frequencies in foci of ATL, the finding of natural infections by flagellates of this parasite or when the parasites are identified as Leishmania (Viannia) sp. in areas where the human cases have been attributed to it, other phlebotomine species have been implicated in the transmission.

In ATL endemic areas in the state of São Paulo, the sand fly species Nyssomyia intermedia, Nyssomyia neivai, Nyssomyia whitmani, Migonemyia migonei, Pintomyia fischeri and Pintomyia pessoai have been indicated as possible vectors of $L$. (V.) braziliensis [10,11]. Pintomyia fischeri and $M g$. migonei are species widely distributed in São Paulo state and are noteworthy as they are highly anthropophilic, presenting considerable density in woodland and peridomiciliary environments $[12,13]$.

Beyond that, Pi. fischeri has been indicated as a possible vector of the ATL agent [12] due to its susceptibility to experimental infection [14] and in the state of Espírito Santo, its natural infection by $L$. (V.) braziliensis has been demonstrated [15].

Expapillata firmatoi is an anthropophilic species which bites humans in both the diurnal and nocturnal periods and is one the most frequent species in the northeastern region of São Paulo state [16]. It has been suspected of being a vector of Leishmania (Leishmania) infantum in foci of visceral leishmaniasis in Rio de Janeiro [17] and its presence although in low densities is frequently cited in research undertaken in these two states and also in Paraná.

Psychodopygus ayrozai is a sandfly frequently collected in the Atlantic biome and is highly anthropophilic [18-20]. In Amazonian region it has been implicated as a vector of Leishmania naiffi [21,22].

Beyond its vectorial competence, the vectorial capacity of a hematophagous insect involves other parameters, such as density of the insect population in relation to the host, the biting habit (measured by the proportion of females which feed on a particular host divided by the duration of the gonotrophic cycle), the survival rate, the period of extrinsic incubation of the parasite and the proportion of the infected insects which became infective [23-25].

The obtaining of such parameters contributes to the assessment of the potential of phlebotomine populations in the transmission of ATL agents, the basis for the formulation of measures of prevention and control of this disease. Thus, this study sought to assess some parameters of anthropophilic species of sand fly occurring in São Paulo state: Pi. fischeri, Mg. migonei Ny. intermedia, Ny. whitmani, Ex. firmatoi and Ps. ayrozai under laboratory conditions for investigate their potential as vectors of $L$. braziliensis. These parameters comprise the proportion of females which feed on a susceptible host (hamster), duration of the gonotrophic cycle, the rate of infection by this parasite; the proportion of females with late-stage infection forms among those infected by this parasite and the duration of the extrinsic incubation period.

\section{Methods}

The species analyzed were captured in São Paulo state (SP), Brazil, in forest or peridomiciles close to the forest edge, in several localities within three regions (Figure 1):

Mogi Guaçu Valley region - northeastern SP - On a smallholding in the municipality of Mogi-Guaçu (22 20.041' S, 46 50.755' W; $671 \mathrm{~m}$ a.s.l. Ex. firmatoi, $\mathrm{Mg}$. migonei and Ny. whitmani were collected at this site.

Greater São Paulo metropolitan region- eastern SP: at three sites: 1$)$ on a smallholding $\left(23^{\circ} 37.656^{\prime} \mathrm{S}, 46^{\circ} 53.164^{\prime}\right.$ W; 808 m. a.s.l) in Embu das Artes municipality; 2) on a smallholding (233' $28^{\prime \prime} \mathrm{S}, 46^{\circ} 53^{\prime} 29^{\prime \prime} \mathrm{W}, 821 \mathrm{~m}$ a.s.l.) in Cotia municipality and 3) in the Parque Estadual da Cantareira (2326' 50.13" S, 46³7' 59.87" W; .843 m. a.s.l.) São Paulo municipality. Mg. migonei, Pi. fischeri and Ps. ayrozai were collected in this region.

Ribeira Valley region- southeastern SP. On a small

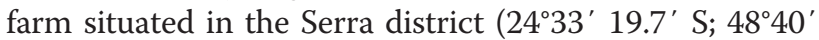
42" W; $198 \mathrm{~m}$ a.s.l.) in Iporanga municipality. $\mathrm{Mg}$. migo$n e i, N y$. intermedia, Ny. neivai and Pi. fischeri were collected at this site. 


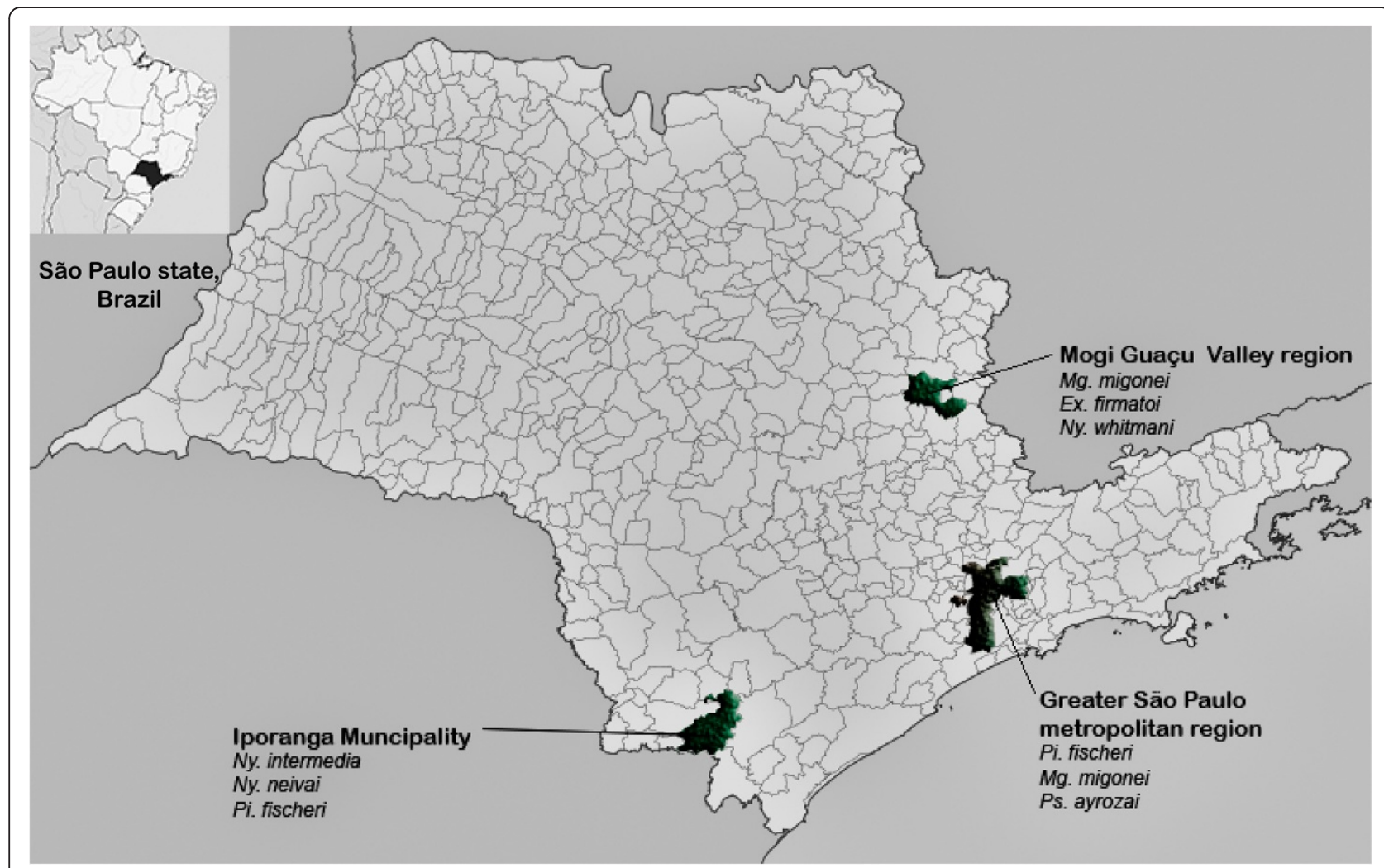

Figure 1 Localities where the sand flies species were captured in São Paulo state (SP), Brazil.

The collections were undertaken with modified black and white Shannon traps [26] installed from 18:00 to 23:00 hours and also with automatic modified CDC light traps, to which a small nylon cage $(20 \mathrm{~cm} \times 20 \mathrm{~cm} \times$ $20 \mathrm{~cm}$ ) was attached by means of a sleeve of $\mathrm{ca} .40 \mathrm{~cm}$ in length, from 18:00 to 06:00 hours.

In the Shannon traps, the insects were captured with a Castro aspirator and the specimens were transferred to small nylon cages in which they were transported to the laboratory. The cages with the insects captured with CDC and Shannon traps were covered with damp towels to maintain the humidity. Hamsters were introduced into the cages in the Laboratorio de Entomologia em Saúde Pública/Phlebotominae of the Faculdade de Saúde Pública of the Universidade de São Paulo (LESP/FSP/ USP) so that the females could feed and egg-laying be stimulated. The insects were maintained in a room at temperatures of $25 \pm 1^{\circ} \mathrm{C}$ and humidity $c a$. $80 \%$. The rearing of sandflies to obtain first- generation specimens was performed as described by [27].

Some first-generation specimens were used in the experiments with hamsters infected by L.(V.) braziliensis (strain MHOM/BR/1995/M15280), maintained in the Laboratório de Patologia de Moléstias Infecciosas of the Faculdade de Medicina of the Universidade de São Paulo
(LIM-50-FMUSP). The experimental infections were undertaken in the LESP/FSP/USP.

The procedures for obtaining the parameters investigated were:

\section{- Proportion of females feeding on the host (hamster)}

Females and males of each of the seven species were released into a nylon cage, where a non-infected or infected hamster under anesthetic was laid supine for about one hour, in the evening. The anesthetic was applied in accordance with the animal's body weight: ketamine $(15 \mathrm{mg} / \mathrm{kg})+$ xilazine $(0.05 \mathrm{mg} / \mathrm{kg})$. In each experiment one hamster was exposed.

\section{- Duration of the gonotrophic cycle}

The females after feeding on the hamsters were individually placed in a vial $(2.5 \mathrm{~cm}$ in diameter and $7 \mathrm{~cm}$ in height) which was covered with a nylon cloth above which was a cover with a central hole through was introduced a small cotton swab moistened with sugar solution. The females were maintained in styrofoam boxes at a room temperature of $25^{\circ} \pm 1^{\circ} \mathrm{C}$ and humidity ca. $80 \%$ and were observed twice daily, in the morning and early evening. The duration of the gonotrophic cycle was estimated by the median time (days) 
elapsed between blood feeding in hamsters and egg laying.

\section{- Experimental infections of the sandfly species by Leishmania braziliensis}

Males and females of each of the sand fly species were released together in a cage on the floor of which an infective anesthetized hamster (having a sore on each of its hind paws) was laid supine for about one hour in the evening. In each infection experiment one hamster was exposed. In the majority of experiments, the hamsters had their bodies covered with a nylon cloth, so that the female insects might bite only the hind paws with the wound. However, in one experiment with $P i$. fischeri two hamsters were exposed simultaneously in two different cages, one with uncovered body, and the other only with exposed hind legs. The female dissection to expose the gut (to observe flagellates) and spermathecae (to identify the sandfly species) was carried out on a slide containing a drop of saline under a stereoscope (magnitude 60x). A cover glass covered the gut and genitalia which were examined under the microscope (magnification $400 \times$ ). For a better view of the spermathecae and the flagellates in the gut a slight pressure was applied to the coverslip with the tip of a forceps. The dissection of the females which died naturally during the night was undertaken at 08:00 and of those which died during the day at 20:00 hours, approximately. The rate of infection of each sand fly species was calculated by the number of females with flagellates in their anterior, median and/or posterior gut observed under the microscope, divided by the total of engorged females. The identification of metacyclic promastigotes (late-stage infection forms) was undertaken considering the morphology of the flagellates: elongated body presenting flagellum three or more times longer than the body $[28,29]$. The frequencies of potentially infective females were obtained by the number of females with at least one infective form of the promastigotes observed in their anterior or thoracic gut divided by the total number of infected females.

\section{- Extrinsic incubation period}

This parameter was obtained using the same methodology described for the infection rate. The extrinsic incubation period was calculated as the median duration (in days) between blood feeding and the presence of metacyclic forms in the anterior (head and esophagus) or thoracic gut (immediately after the estomodeal valve) $[28,29]$.

This study was approved by the Ethics Committee on Animal Research of the Medical School of São Paulo
University (CEP-IMT 057/2009) and the Biosafety Committee of the Faculty of Public Health, University of São Paulo (protocol 2026 OF.COEP/14/10).

\section{Results}

\section{Proportion of females feeding on hamster}

The numbers of experiments and of females, by species and collection locality, to which the hamsters (non-infected or infected) were exposed and the proportion of engorged females are given in Table 1.

In the experiments with non-infected hamster, Pi. fischeri was the species which underwent the greatest number of experiments (25) and provided the greatest number of exposed females $(1,844)$ from the three sites in the Greater São Paulo region; the median of the proportions of engorged females varying between 0.46 and 0.77 . For $M g$. migonei, a total of 127 females were exposed in nine experiments with specimens from Embu das Artes and Mogi Guaçu; the median of the proportion of females engorged varying between nil and 0.6 . Regarding the two other species from Mogi Guaçu, three experiments were undertaken with $N y$. whitmani involving 1,164 exposed females; the median value of the proportion of females engorged being 0.33 . As for Ex. firmatoi, four experiments were carried out with a total of 141 females; the median value of engorged females being 0.42. Four experiments were undertaken involving 19 females of Ps. ayrozai, none of them engorged (Table 1).

Regarding the experiments involving hamsters with only the ulcerated paws exposed infected by $L$. $(V$.) braziliensis, for Pi. fischeri, 11 experiments were carried out, seven with females from Greater São Paulo (Embu das Artes and Cantareira) and four from Ribeira Valley (Iporanga), with a total of 305 engorged females out of a total of 682 exposed (0.45); the median values of the proportion varying between 0.22 and 0.46 . Regarding Mg. migonei, a total of 26 engorged females of 73 exposed (0.36) was observed in a total of nine experiments with specimens from the three regions; the median proportion of females engorged varying between 0.20 and 0.88 , the highest proportion of them being from one of the experiments with F1 females raised in the laboratory. As for the two species from the Ribeira Valley, $N y$. intermedia and $N y$. neivai, six and seven experiments were, respectively, undertaken with each. For $N y$. intermedia 852 females were exposed while for $N y$. neivai, 99; the median values of engorged females being respectively 0.32 and 0.25 . For $N y$. whitmani, only one experiment was carried out with 93 females exposed and with a proportion of engorged females of 0.31.The lowest proportion of engorged females 5/232 (0.02) was observed for Ps. ayrozai (Table 1).

In the single experiment undertaken with Pi. fischeri blood feeding on a hamster infected with its body uncovered, 172 females were exposed and 133 engorged (0.77). 
Table 1 Sand fly females by speciesand locality fed on hamsters both infected and uninfected by Leishmania (Viannia) braziliensis and numbers of experiments

\begin{tabular}{|c|c|c|c|c|c|c|c|c|c|}
\hline \multirow[b]{2}{*}{ Species } & \multirow{2}{*}{$\begin{array}{c}\text { Exposed hamster's } \\
\text { condition } \\
\text { Localities }\end{array}$} & \multicolumn{4}{|c|}{ Uninfected } & \multicolumn{4}{|c|}{ Infected, with only ulcerated legs exposed } \\
\hline & & $\begin{array}{c}\text { Numbers of } \\
\text { females exposed }\end{array}$ & $\begin{array}{c}\text { Numbers of } \\
\text { females engorged }\end{array}$ & $\begin{array}{l}\text { Median proportions } \\
\text { of engorged females }\end{array}$ & $\begin{array}{l}\text { Numbers of } \\
\text { experiments }\end{array}$ & $\begin{array}{c}\text { Numbers of } \\
\text { females exposed }\end{array}$ & $\begin{array}{c}\text { Numbers of } \\
\text { females engorged }\end{array}$ & $\begin{array}{l}\text { Median proportions } \\
\text { of engorged females }\end{array}$ & $\begin{array}{l}\text { Numbers of } \\
\text { experiments }\end{array}$ \\
\hline Ex. firmatoi & Mogi Guacu & 141 & 63 & 0.42 & 4 & 21 & 4 & 0.19 & 1 \\
\hline \multirow[t]{4}{*}{ Mg. migonei } & Embu das Artes & 28 & 6 & 0 & 5 & 12 & 4 & 0.20 & 5 \\
\hline & Lab (M.Guaçu) & $\ldots$ & $\ldots$ & $\ldots$ & $\ldots$ & 8 & 7 & 0.88 & 1 \\
\hline & Iporanga & $\ldots$ & $\ldots$ & $\ldots$ & $\ldots$ & 21 & 8 & 0.38 & 2 \\
\hline & Mogi Guaçu & 99 & 65 & 0.60 & 4 & 32 & 7 & 0.22 & 1 \\
\hline Ny. intermedia & Iporanga & & $\ldots$ & $\ldots$ & $\ldots$ & 852 & 311 & 0.32 & 6 \\
\hline Ny. neivai & Iporanga & $\ldots$ & $\ldots$ & $\ldots$ & $\ldots$ & 99 & 45 & 0.25 & 7 \\
\hline Ny. whitmani & Mogi Guaçu & 1164 & 384 & 0.33 & 3 & 93 & 22 & 0.31 & 1 \\
\hline \multirow[t]{4}{*}{ Pi. fischeri } & Cotia & 269 & 128 & 0.59 & 9 & $\ldots$ & $\ldots$ & $\ldots$ & $\ldots$ \\
\hline & Embu das Artes & 449 & 202 & 0.46 & 14 & 347 & 151 & 0.22 & 5 \\
\hline & Cantareira & 408 & 310 & 0.77 & 2 & 203 & 93 & 0.46 & 2 \\
\hline & Iporanga & $\ldots$ & $\ldots$ & $\ldots$ & $\ldots$ & 132 & 61 & 0.32 & 4 \\
\hline Ps. ayrozai & Cantareira & 19 & 0 & 0.00 & 4 & 232 & 5 & 0.02 & 1 \\
\hline
\end{tabular}




\section{Gonotrophic cycle}

The gonotrophic cycles of Ex. firmatoi, Mg. migonei, $\mathrm{Ny}$. intermedia, Ny. neivai, Ny. whitmani and Pi. fischeri are given in Table 2 . This period varied from 4 to 8 days; the median for $M g$. migonei was 7 days, for $N y$. neivai and $N y$. whitmani 4 days and for the other three species 5 days.

\section{Infection and late-stage infection rates}

The infection rates of Ex. firmatoi, Mg. migonei, $N y$. intermedia, Ny. neivai, Ny. whitmani and Pi. fischeri by L. braziliensis and their extrinsic incubation periods in these six sand fly species which blood fed on hamsters infected with only the ulcerated paws exposed are presented in Table 3. A total of 635 females representing the six sand fly species were observed, Ex. firmatoi (4.3\%), Mg. migonei (3.9\%), Ny. intermedia (40.5\%), Ny. neivai (7.1\%), Ny. whitmani (9.6\%) and Pi. fischeri (34.6\%). The highest infection rate was observed for $N y$. whitmani (34.4\%) and the lowest for $N y$. neivai (13.3\%) and Ny. intermedia (6.2\%). Ex. firmatoi, Mg. migonei and Pi. fischeri presented intermediate values between $22.2 \%$ $24.0 \%$.

For Ps. ayrozai, no infected female was observed among the five which engorged on an infected hamster.

No females of $M g$. migonei survived beyond the 5th day after the blood meal, nor those of Ex. firmatoi and $N y$. whitmani after the 6th day or those of $N y$. intermedia, Ny. neivai and Pi. fischeri beyond the 7th day.

For Ny. intermedia and Ny. whitmani, $100 \%$ of the females infected with flagellates presented late-stage infection forms, while only $50 \%$ did so in $\mathrm{Mg}$. migonei; intermediate values $(70.6 \%-83.3 \%)$ being observed for Pi. fischeri, $N y$. neivai and Ex. firmatoi.

As regards the females of Pi. fischeri exposed to hamsters infected by L. (V.) braziliensis with its whole body exposed - of a total of 109 females dissected only 6 (5.5\%) developed infection and in $83.3 \%$ of these $(5 / 6)$ the forms were potentially infective. In this experiment, $14 / 30$ (47\%) females dissected presented blood in the gut until the $4^{\text {th }}$ day after feeding. No further remnants

Table 2 Gonotrophic cycles of Ex. firmatoi, Ny. intermedia, $\mathrm{Ny}$. neivai, $\mathrm{Ny}$. whitmani and Pi. fischeri under laboratory conditions

\begin{tabular}{lcccc}
\hline Species & N & $\begin{array}{c}\text { Minimum } \\
\text { (days) }\end{array}$ & $\begin{array}{c}\text { Maximum } \\
\text { (days) }\end{array}$ & $\begin{array}{c}\text { Median } \\
\text { (days) }\end{array}$ \\
\hline Ex. firmatoi & 46 & 3 & 7 & 5 \\
Ny. intermedia & 48 & 4 & 7 & 5 \\
Ny. neivai & 44 & 3 & 6 & 4 \\
Ny. Whitmani & 62 & 3 & 7 & 4 \\
Mg. migonei & 50 & 7 & 8 & 7 \\
Pi. fischeri & 150 & 4 & 8 & 5 \\
\hline
\end{tabular}

of blood were observed in the gut of the females dissected after the $5^{\text {th }}$ day (Table 4 ).

\section{Extrinsic incubation period}

Migonemyia migonei presented potentially infective forms on the 5th day after feeding, but the other species' potentially infective forms were observed as from the $4^{\text {th }}$ day (Table 2). However, for Pi. fischeri feeding on infected hamsters with the body uncovered the extrinsic incubation period occurred as from the 6th day; but only three females died on the 5 th day.

\section{Discussion}

\section{Blood feeding habit}

For the female insects which present the gonotrophic concordance (each blood meal is followed by one oviposition) frequently observed among sand fly species [30], the vector's biting habit could be estimated indirectly by the proportion of insects which feed on the source host or one susceptible to infection by a particular agent, divided by the period (in days) of the gonotrophic cycle [24]. This value being a quotient of these two measurements, for populations with disharmonic gonotrophic concordance (each egg-laying is dependent on two or more blood meals - as, e.g., in the case of Phlebotomus papatasi) [31] the biting habit only contributes to raising the vectorial capacity if the period of extrinsic incubation is completed before the next meal. Populations which present this characteristic have greater epidemiological significance as potential vectors. However, the period of extrinsic incubation has been shown to be very close to that of the gonotrophic cycle. This latter, in sand flies which feed on warm-blooded animals, varies from 4 to 10 days, frequently from the seventh to the tenth day [30].

In this study the median duration of the gonotrophic cycle for the species studied was between the fourth and fifth day (Table 4), however, this parameter may vary depending on the temperature. For $N y$. neivai under natural conditions it was estimated at 8 days [32].

In natural circumstances, apart from the preference of hematophagous insects for feeding on particular hosts, the biting rate is influenced by the diversity, density and spatial and temporal distribution of the blood source populations [33-35].

Although in this present study one single type of host (a rodent) was exposed, it was observed that of the seven sand fly species investigated, Ps. ayrozai showed the lowest biting rate, suggesting the low attractiveness of this animal for this species. This low attractiveness was evidenced because no Ps. ayrozai female bit the noninfected hamster with its body uncovered and only $2 \%$ of the females bit the infected paws when they were exposed (Table 1). Similarly, the low attractiveness of another 
Table 3 Numbers of females by sandfly species, according to the number of days elapsed between their feeding and dissection, and the infected and potentially infective condition by Leishmania (Viannia) braziliensis

\begin{tabular}{|c|c|c|c|c|c|c|c|c|c|c|c|c|}
\hline \multirow{2}{*}{$\begin{array}{l}\text { Species } \\
\text { Day after feeding }\end{array}$} & \multicolumn{2}{|c|}{ Ex. firmatoi } & \multicolumn{2}{|c|}{ Mg. migonei } & \multicolumn{2}{|c|}{ Ny. intermedia } & \multicolumn{2}{|c|}{ Ny. neivai } & \multicolumn{2}{|c|}{ Ny. whitmani } & \multicolumn{2}{|c|}{ Pi. fischeri } \\
\hline & dis & inf (pif) & dis & inf (pif) & dis & $\inf (p i f)$ & dis & inf (pif) & dis & inf (pif) & dis & inf (pif) \\
\hline $1 s t$ & $\ldots$ & $\ldots$ & 1 & 0 & 4 & 0 & $\ldots$ & $\ldots$ & $\ldots$ & $\ldots$ & 7 & 0 \\
\hline $2 n d$ & $\ldots$ & .. & 3 & 0 & 28 & 0 & $\ldots$ & ... & 6 & 0 & 19 & 0 \\
\hline $3 r d$ & 3 & $1(0)$ & 0 & 0 & 10 & 0 & 1 & 0 & & $\ldots$ & 17 & $4(0)$ \\
\hline 4th & 9 & $1(1)$ & 7 & 1 & 75 & $4(4)$ & 8 & $1(1)$ & 16 & $5(5)$ & 49 & $12(3)$ \\
\hline 5 th & 14 & $4(4)$ & 14 & $5(3)$ & 122 & $8(8)$ & 30 & $3(3)$ & 35 & $16(16)$ & 58 & $19(17)$ \\
\hline 6th & 1 & 0 & $\ldots$ & $\ldots$ & 13 & $2(2)$ & 5 & $1(1)$ & 4 & 0 & 36 & $11(11)$ \\
\hline 7th & $\ldots$ & $\ldots$ & $\ldots$ & $\ldots$ & 5 & $2(2)$ & 1 & $1(1)$ & $\ldots$ & $\ldots$ & 34 & $5(5)$ \\
\hline Total & 27 & $6(5)$ & 25 & $6(3)$ & 257 & $16(16)$ & 45 & $6(5)$ & 61 & $21(21)$ & 220 & $51(36)$ \\
\hline Infected (\%) & 22.2 & 24.0 & 6.2 & 13.3 & 34.4 & 23.2 & & & & & & \\
\hline Potentially Infective/infected (\%) & \multicolumn{2}{|c|}{83.3} & \multicolumn{2}{|r|}{50.0} & \multicolumn{2}{|c|}{100.0} & \multicolumn{2}{|r|}{83.3} & \multicolumn{2}{|r|}{100.0} & \multicolumn{2}{|r|}{70.6} \\
\hline Surviving $\%$ after egg- laying & \multicolumn{2}{|r|}{3.7} & \multicolumn{2}{|r|}{0} & \multicolumn{2}{|c|}{7.0} & \multicolumn{2}{|r|}{80.0} & \multicolumn{2}{|r|}{65.6} & \multicolumn{2}{|r|}{31.8} \\
\hline
\end{tabular}

dis = dissected females; inf = infected females; $($ pif) = potentially infective females; ... not observed.

* $=$ median of gonotrophic cycle period.

rodent (a guinea-pig) to this species was observed in natural conditions ( 0.57 insect/night/bait) when compared to that of the armadillo (Dasypus novemcinctus) (73.7/ insects/night/bait) in Montagne des Chevaux, French Guyana [36].

Psychodopygus ayrozai is one of the most frequent species in primary Atlantic forest, being collected both at ground level and in the forest canopy, and has been shown to be anthropophilic [20,37-40]. Despite these characteristics of this sand fly, the transmission of Leishmania to the human population in primary Atlantic forests is low and has been associated with the zoophilic habits of the vectors [39]. However, if the weak hamster attractiveness to Ps. ayrozai observed in the laboratory

Table 4 Numbers of females of Pintomyia fischeri dissected by post-blood meal on a hamster infected by Leishmania braziliensis with the whole body exposed, presence of blood in the gut, infected by the parasite and presence of late-stage of development promastigotes

\begin{tabular}{lcccc}
\hline $\begin{array}{l}\text { Day of the } \\
\text { blood meal }\end{array}$ & Dissected & $\begin{array}{c}\text { With blood } \\
\text { in the gut }\end{array}$ & Infected & $\begin{array}{c}\text { Late-stage } \\
\text { development } \\
\text { promastigotes }\end{array}$ \\
\hline 2nd & 2 & 2 & 0 & 0 \\
3rd & 7 & 7 & 0 & 0 \\
4th & 30 & 14 & 1 & 0 \\
5th & 3 & 0 & 0 & 0 \\
6th & 39 & 0 & 3 & 3 \\
7th & 21 & 0 & 1 & 1 \\
8th & 7 & 0 & 1 & 1 \\
Total & 109 & 23 & 6 & 5 \\
\% & & 12.8 & 5.5 & 4.6 \\
\hline
\end{tabular}

experiments can be extrapolated to wild rodents (significant reservoirs of Leishmania braziliensis) [41], the low transmission of this Leishmania in this biome could also be explained as due to the preference of this sand fly for feeding on animals which play little or no role as reservoirs of the cutaneous leishmaniasis agents (e.g. armadillos) in this environment.

In the present study, for the sand fly species captured in the same localities, challenged to bite the hamsters with only the infected paws or with the whole body uncovered: Pi. fischeri from Embu das Artes and Cantareira, Ex. firmatoi from Mogi Guaçu and Mg. migonei from Embu das Artes and Mogi Guaçu, it was observed that the proportion of engorged females was also greater on the uncovered hamster than on that which had only its paws exposed (Table 1). This may be explained by the larger exposed area and consequently lower competitiveness for space for landing to bite. However, the infection rate was greater when only the paws with sores were exposed. This seems to show that the Leishmania braziliensis is concentrated in the sore; even so the infection rate was greater than that observed for experimental infection by Leishmania tropica in Phlebotornus duboscqi females fed on hamster lesions [42]. A low proportion of those engorged was observed when few females were used in the experiments. This fact may be associated with the liberation of pheromones of aggregation which stimulate the landing on the host and the haematophagy $[43,44]$.

Regarding $N y$. neivai, this species was considered a junior synonym of $N y$. intermedia for nearly 70 years [45]. Thus, despite there being some information in the literature about the species' attractiveness and the related experimental infection it probably refers, in fact, to $N y$. intermedia s. lat. in the Southeast region of Brazil, 
$N y$. intermedia and $N y$. neivai are anthropophilic species and are captured in high frequencies in the intra and peridomicile. Nyssomyia intermedia is associated with the coastal region but in São Paulo state Ny. neivai occurs exclusively in the plateau region and sympatrically with $N y$. intermedia in the Ribeira Valley region $[20,46]$. The anthropophily of $N y$. intermedia s. lat. in a forested environment in the Ribeira Valley region (sympatric area of $N y$. neivai and $N y$. intermedia) was estimated at 9.3/ females/night [47] and for $N y$. intermedia populations in Espírito Santo state in an area far from the coast, an average of 6.7 insects/night was observed [48]. However, in a forested coastal area, the attractiveness of human for this species both in São Paulo and Espírito Santo states was greatly reduced $[16,48]$. For these two species of this sympatric area the proportions of engorged females were very close (Table 1$)$.

\section{Infection rate and infective potential}

In the experiments involving the six sand fly species with positive results for $L$. $(V$.) braziliensis infection, the median rate of infected insects varied from 6.2 to $34.4 \%$; the lowest of them being for $N y$. intermedia and the highest for $N y$. whitmani. The median value of $6.2 \%$ found for wild females of $N y$. intermedia was much lower than the infection rates observed for females of the laboratory colony ( $39^{\text {th }}$ generation) whose forebears came from Rio de Janeiro state $[49,50]$. They observed an infection rate above $30 \%$ for females fed on an infected hamster or artificially on chicken-skin membrane. This disparity may be related to the population differences between sand fly species, parasite load or size and time of exposure of the ulcered hamster. However, this median value was greater than that observed in experiments with laboratory females coming from the same area as those of the present study and fed on a hamster infected by Leishmania (Leishmania) amazonensis 1/26 (3.8\%) [51].

Nyssomyia neivai presented a median value 2.1 times greater than that of Ny. intermedia (Table 2). However, both species presented much lower values than those for $N y$. intermedia s. lat. whether obtained in the laboratory (F1) or in the wild (varying from $67 \%$ to $76 \%$ ), also coming from the Ribeira Valley region [52]. Although the proportion of potentially infective females was lower for $N y$. neivai (83.3\%) than for $N y$. intermedia (100.0\%), our result suggests that the $N y$. neivai population presents a higher probability of infection and infectivity by $L .(V$.) braziliensis than Ny. intermedia. This because the exposition of the infected hamster to these two sand fly species collected together took place simultaneously.

Despite the sample of $N y$. neivai having been considerably inferior in number to that of $N y$. intermedia, the mortality in this period was greater for $N y$. intermedia
(16\%) than for $N y$. neivai (2.2\%). Considering the infectivity and the proportion of engorged females surviving after the complete extrinsic incubation period for $L$. braziliensis, our results suggest that $N y$. neivai presents an infective survival rate greater than $N y$. intermedia, having, therefore, a greater probability of taking a second infective meal on a susceptible host. Although wild females of unknown physiological state were used in the experiments, which might imply different mortality rates, a study of Ny. intermedia s. lat. in the Ribeira Valley, where the two species are sympatric, indicated that of 26,383 females captured, $99.4 \%$ of them were nulliparous, which suggests that there was a high proportion of young females among them [53]. Therefore, in the light of this information, a great proportion of young specimens among the females used in the experiments could be expected and so the age factor had little effect on the mortality rate.

Previous studies in the Ribeira Valley region showed that the ratio between $N y$. intermedia and $N y$. neivai in a peridomicile $180 \mathrm{~m}$ from forest was 3.5/1.0, while that in a peridomicile of a more anthropic area $700 \mathrm{~m}$ from the forest was 1.5/1.0 [20]. This information suggests that $N y$. neivai is more adapted to the anthropic environment than is $N y$. intermedia. Thus, if both species present the same degree of anthropophily in areas of great human influence, $N y$. neivai presents a transmission potential of Leishmania sp. slightly higher than that of $N y$. intermedia, while in a more preserved area that of $N y$. intermedia would be double that of $N y$. neivai.

As regards $N y$. whitmani, a recognized vector of $L$. (V.) braziliensis [54], the values here found confirm its susceptibility to infection and the development of potentially infective forms (100\%); it was, further, found to have the highest infection rates. An experimental infection rate for this sand fly species of $2 \%(1 / 46)$ was observed when it was fed on an ulcer on an infected monkey of the Rhesus genus [14]. On the other hand, specimens of this sand fly species from Bahia feeding on an ulcer on a dog present rates varying from 1.8 to $8.3 \%$ [38]. The data here presented for Ny. intermedia and Ny. whitmani show that the infection rate of this latter is 5.3 times greater. However, for both species a similar proportion (100.0\%) of the females harboring late-stage infection forms among those infected was observed (Table 1). This, together with the greater degree of attachment of the procyclic forms to the gut epithelium in $N y$. whitmani than in $N y$. intermedia ( $\sim$ folds) [55] seems to explain our results, since a lower level of gut attachment of the procyclics reduces the chances of success of their later phases. Once this barrier is overcome, the parasites in both species would have similar chances of attaining the metacyclic stage. However, distinct parasite loads among hamsters exposed to the bite of these two species cannot be ignored when we seek to explain their different infective rates. 
Pintomyia fischeri is a common species in foci of cutaneous leishmaniasis in the Southeast, South and Northeast regions of Brazil [10-13]. Although it is more frequently found in forests, it also occurs in anthropic environments [11-13]. Despite its having been considered a possible vector of $L$. (V.) braziliensis on the basis of its high degree of anthropophily, frequency in the intradomicile and susceptibility to experimental infections when fed on monkeys of the Rhesus genus $(0.4 \% ; 1 / 246)$ [12], only recently has its natural infection by L. braziliensis or by L. (Viannia) been demonstrated [15,56-58]. The infection rate of $23.2 \%$ observed for Pi. fischeri in the present study reinforces the hypothesis of its participation in the transmission of this parasite, mainly in the Greater São Paulo area, where it predominates over the other species [12,13,59] and is anthropophilic [12,13]. Pi. fischeri also predominated in captures on human bait in a residual forest close to domiciles situated in the central-northeast region (in an area of Paleozoic depression, 600-800 m a.s.l.) of São Paulo state and also in Espírito Santo state in forest close to the coast, but in this latter area in an anthropic environment its frequency was less than that of Ny. intermedia, and in a municipality (Afonso Claudio) further inland in Espirito Santo state its frequency was inferior to that of other vectors [48].

Migonemyia migonei, an inhabitant of primary and secondary forests, which also frequents human dwellings, feeding avidly on humans and domestic animals (dogs and birds), contributed $14 \%$ of the sand fly specimens collected in São Paulo state in the early 1940s [12]. Its natural infection rate possibly by $L$. $(V$.) braziliensis $(0.2 \% ; 6 / 2842)$ was observed in the northwest region of São Paulo state, a highly endemic area [14] and currently this species is considered a secondary vector of the cutaneous leishmaniasis agent in this state [10]. In Baturité municipality in Ceará state it was the third most frequent species and was found to be naturally infected with $L$. (V.) braziliensis [60,61]; in two foci in Rio de Janeiro municipality it was the second most prevalent species and found naturally infected with $L$. (V.) braziliensis [62] and in São Vicente Férrer in Pernambuco state it was the most prevalent species in a domiciliary environment and found naturally infected [63]. In the present study an infection rate of $24.0 \%$ was obtained lower than the approximately $50 \%$ observed in sand flies of this species fed artificially [64]. So in the light of various factors: the infection and potentially infective rates observed in the present study, the rodents' attractiveness to this species under natural conditions [48] and several findings of specimens with natural infection by $L$. (V.) braziliensis or Leishmania (Viannia) sp, this sand fly may be seen as in fact playing an important role in the transmission of cutaneous leishmaniasis agents.
Expapillata firmatoi presented an infection rate of $22.2 \%$. However, despite its anthropophilic habit of biting in both diurnal and nocturnal periods and its being one of the most frequent species in the northeastern region of São Paulo state [39], this species has not been found naturally infected by Leishmania. However, in forest in Espírito Santo state (Afonso Claudio municipality) it was little attracted to human bait, but was the species most attracted to Disney traps baited with the primates Cebus apela and Callithrix geoffroy, marsupials (Marmosa cinerea, Philander opossum and Metachirus nudicaudatus) and the rodent Agouti paca [48]. Thus its role as a potential vector of cutaneous leishmaniasis agents still calls for elucidation.

Although the dissection technique used in this present study could lead to the underestimation of infection rates for the sand fly species observed, as can be inferred from some studies that beyond this technique also used molecular tests [63-67] and also because the females were dissected as they were dying (thus increasing the chances of degradation of the parasite with negative results under microscopic examination), it was possible on the other hand to observe the potentially infective promastigote in the thoracic mid-gut of the sand fly and the extrinsic incubation period compatible with the transmission of the parasite during the next blood meal. This information together with the data related to high frequencies, anthropophily, presence in domiciliary environment and the findings of natural infection by $L$. (V.) braziliensis or L. (Viannia) sp. of the sand fly species investigated, strengthens the evidence incriminating them as vectors of $L$. braziliensis, whether acting in isolation or in sympatry in foci scattered over a large part of Brazil, Argentina and Paraguay.

\section{Conclusions}

Of the seven species investigated, Ex. firmatoi, $M g$. migonei, Ny. intermedia, Ny. neivai, Ny. whitmani, Pi. fischeri and Ps. ayrozai, the first six presented a relatively high proportion feeding on hamsters and shown to be susceptible to experimental infection by $L$. (V.) braziliensis. These also presented promastigotes in late-stage of development in their thoracic mid-gut and the extrinsic incubation period compatible with the gonotrophic cycle. Our results together with other parameters of their behavior under natural conditions, suggest the potential role of Ex. firmatoi as vector of this parasite and reinforce that of $\mathrm{Mg}$. migonei, Pi. fischeri, Ny. neivai, Ny. intermedia and Ny. whitmani in the areas in which they occur.

\section{Competing interests}

The authors declare that they have no competing interests.

\section{Authors' contributions}

EABG, FGO designed and supervised the study. MMCSD, FGO, EABG, CCG, $\mathrm{COL}$ undertook field and laboratory activities. EABG, FGO, analyzed the data, 
drafted and revised the manuscript. All the authors revised and approved the final version of the manuscript.

\section{Acknowledgments}

We are grateful to Claudio Casanova for his technical assistance and help during investigations and to the owners of the smallholdings investigated for permitting us to make the captures. We thank the São Paulo Research Foundation (FAPESP) for their financial support, grant 2009/53414-1 and CNPq forMMCSD's fellowship.

\section{Author details}

${ }^{1}$ Postgraduate Program in Public Health, School of Public Health, University of São Paulo - USP, São Paulo, SP, Brazil. ²Department of Pathology, University of São Paulo Medical School, São Paulo, SP, Brazil. ${ }^{3}$ Professional Improvement Program, PAP-FUNDAP-Department of Epidemiology/School of Public Health, University of São Paulo- USP, São Paulo, Brazil. ${ }^{4}$ Department of Epidemiology, School of Public Health, University of São Paulo - USP, São Paulo, SP, Brazil.

Received: 10 December 2013 Accepted: 12 March 2014 Published: 31 March 2014

\section{References}

1. Dejeux P: Leishmaniasis: current situation and new perspectives. Comp Immunol Microbiol Infect Dis 2004, 27:305-318.

2. Brasil. Ministério da Saúde: Manual de Vigilância da Leishmaniose Tegumentar Americana. 2nd edition. Brasil: Ministério da Saúde; 2007.

3. PAHO (Pan American Health Organization): Leishmaniases: Epidemiological Report of the Americas, Report Leishmaniases Nํ 1 - 2013; April. [http://www. paho.org/leishmaniasis]

4. Bailey MS, Bailey MS, Lockwood DNJ: Cutaneous leishmaniases. Clin Dermatol 2007, 25:203-211.

5. WHO: World Health Report 2002: Reducing Risks, Promoting Healthy Life. Geneva: World Health Organization; 2002.

6. Tolezano JE: Ecoepidemiological aspects of American cutaneous leishmaniases in the State of São Paulo, Brazil. Mem Inst Oswaldo Cruz 1994, 89:427-434

7. Alvar J, Vélez ID, Bern C, Herrero M, Desjeux P, Cano J, Jannin J, den Boer M, the WHO Leishmaniasis Control Team: Leishmaniasis worldwide and global estimates of its incidence. PLOS ONE 2012, 7(5):e35671.

8. Lainson R, Shaw JJ: New world leishmaniasis. In Topley \& Wilson's Microbiology and Microbial Infections, Volume 2. Edited by Cox FEG, Wakelin D, Gillespie SH, Despommier DD. London: Hodder Arnold; 2005:313-349.

9. Ryan L, Lainson R, Shaw JJ: Leishmaniasis in Brazil. XXIV. Natural flagellate infections of sandflies (Diptera: Psychodidae) in Pará state, with particular reference to the role of Psychodopygus wellcomei as the vector of Leishmania braziliensis in the Serra dos Carajás. Trans Roy Soc Trop Med Hyg 1987, 81:353-355.

10. Camargo-Neves VL, Gomes AC, Antunes JL: Correlation of the presence of phlebotominae species (Diptera: Psychodidae) with records of American tegumentary leishmaniasis cases in the state of São Paulo. Brazil. Rev Soc Bra MedTrop 2002, 35:299-306.

11. Shimabukuro PHF, Silva TRR, Ribeiro FOF, Baton LA, Galati EAB: Geographical distribution of American cutaneous leishmaniasis and its phlebotomine vectors (Diptera: Psychodidae) in the state of São Paulo, Brazil. Parasites \& Vectors 2010, 3:121-132.

12. Barretto MP: Observacões sobre a Biologia em Condicões Naturais, dos Flebótomos de São Paulo (Diptera: Psychodidae). São Paulo, Brasil: Tipografia Rossolino; 1943.

13. Moschin JC, SEI IA, Ovallos FG, Galati EAB: Ecological aspects of phlebotomine fauna (Diptera, Psychodidae) of Serra da Cantareira, Greater São Paulo Metropolitan region, state of São Paulo, Brazil. Rev Bras Epidemiol 2013, 16(1):190-201.

14. Pessôa SB, Coutinho JO: Infecção natural e experimental dos flebótomos pela Leishmania braziliensis no Estado de São Paulo. Hospital 1941, 20:25-35.

15. Rocha LSO, Santos CB, Falqueto A, Grimaldi G Jr, Cupolillo E: Molecular biological identification of monoxenous trypanosomatids and Leishmania from anthropophilic sand flies (Diptera: Psychodidae) in Southeast Brazil. Parasitol Res 2010, 107:465-468.
16. Gomes AC, Galati EAB: Aspectos ecológicos da leishmaniose tegumentar americana. 7 - Capacidade vetorial flebotomínea em ambiente florestal primário do sistema da Serra do Mar, região do Vale do Ribeira. Rev Saude Publica 1989, 23(2):136-142.

17. Souza MB, Marzochi MCA, Carvalho RW, Ribeiro PC, Pontes CS, Caetano JM, Meira AM: Ausência da Lutzomyia longipalpis em algumas áreas de ocorrência de leishmaniose visceral no Município do Rio de Janeiro. Cad Saúde Pública 2003, 19(6):1881-1885.

18. Aguiar GM, Soucasaux T: Aspectos da ecologia dos flebótomos do Parque Nacional da Serra dos Órgãos, Rio de Janeiro. I — Freqüência mensal em isca humana (Diptera, Psychodidae: Phlebotominae). Mem Inst Oswaldo Cruz 1984, 79:197-209.

19. Aguiar GM, Medeiros W: Distribuição regional e hábitats das espécies de flebotomíneos do Brasil. In Flebotomíneos do Brasil. Edited by Rangel EF, Lainson R. Editora Fiocruz: Rio de Janeiro; 2003:207-255.

20. Galati EAB, Marassá AM, Gonçalves-Andrade RM, Consales CA, Bueno EMF: Phlebotomines (Diptera, Psychodidae) in the Speleological Province of the Ribeira Valley: 2. Parque Estadual do Alto Ribeira (PETAR), São Paulo State, Brazil. Rev Bras Entomol 2010, 54:477-487.

21. Lainson R, Shaw JJ: Leishmania (Viannia) naiffi sp.n., a parasite of the armadillo, Dasypus novemcinctus (L.) in Amazonian Brazil. AnnParasitol Hum Comp 1989, 64:3-9.

22. Lainson $R$, Shaw JJ, Silveira FT, Souza AAA, de Braga RR, Ishikawa EAY: The dermal leishmaniases of Brazil, with special reference to the eco-epidemiology of the disease in Amazonia. Mem Inst Oswaldo Cruz 1994, 89(3):435-443.

23. Macdonald G: The Epidemiology and Control of Malaria. London: Oxford Univ. Press; 1957.

24. Garrett-Jones C: The human blood index of malaria vectors in relation to epidemiological assessment. Bull. WHO 1964, 30:241-261.

25. Reisen WK: Estimation of vectorial capacity: relationship to disease transmission by malaria and arbovirus vectors. Bull Soc Vector Ecol 1989, 14:67-70.

26. Galati EAB, Nunes VLB, Dorval MEC, Cristaldo G, Rocha HC, GonçalvesAndrade RM, Naufel G: Attractiveness of black Shannon trap for plebotomines. Mem Inst Oswaldo Cruz 2001, 96:641-647.

27. Killick-Kendrick M, Killick-Kendric R: The initial establishment of sandfly colonies. Parassitologia 1991, 33(Suppl 1):315-320.

28. Kamhawi S: Phlebotomine sand flies and Leishmania parasites: friends or foes? Trends inParasitology 2006, 22:439-445.

29. Nieves E, Pimenta PFP: Development of Leishmania(Viannia) braziliensis and Leishmania (Leishmania) amazonensis in the sand fly Lutzomyia migonei (Diptera: Psychodidae). J Med Entomol 2000, 37(1):134-140.

30. Forattini OP: Entomologia Médica. Psychodidae. Phlebotominae. Leishmaniose. Bartonelose. São Paulo: Editora Edgard Blücher Ltda; 1973.

31. Magnarelli LA, Modi GB, Tesh RB: Follicular development and parity in phlebotomine. J Med Entomol 1984, 21(6):681-689.

32. Casanova C, Natal D, Santos FA: Survival, population size, and gonotrophic cycle duration of Nyssomyia neivai (Diptera: Psychodidae) at an endemic area of American cutaneous leishmaniasis in southeastern Brazil. J Med Entomol 2009, 46(1):42-50.

33. Morrison AC, Ferro C, Tesh RB: Host preferences of the sand fly Lutzomyia longipalpis at an endemic focus of American visceral leishmaniasis in Colombia. Amer J Trop Med Hyg 1993, 49(1):68-75.

34. Palit A, Bhattacharya SK, Kundu SN: Host preference of Phlebotomus argentipes and Phlebotomus papatasi in different biotopes of West Bengal, India. Int J Environ Res Public Health 2005, 15(6):449-454.

35. Reisen WK: Landscape epidemiology of vector-borne diseases. Annu Rev Entomol 2010, 55:461-483.

36. Le Pont F: Attractivite du tatou (Dasypus novemcinctus) et des cobayes pour les phlebotomes en Guyane Française. Bull Soc Path Ex 1990, 83:671-676.

37. Aguiar GM, Vilela ML, Schuback PD, Soucasaux T, Azevedo ACR: Aspectos da ecologia dos flebótomos do Parque Nacional da Serra dos Órgãos, Rio de Janeiro. IV - Freqüência mensal em armadilhas luminosas (Diptera, Psychodidae: Phlebotominae). Mem Inst Oswaldo Cruz 1985, 80:465-482

38. Vexenat JA, Barreto AC, Cuba-Cuba CA, Marsden PD: Características epidemiológicas da leishmaniose tegumentar americana em uma região endêmica do Estado da Bahia. III. Fauna flebotomínica. Mem Inst Oswaldo Cruz 1986, 81:293-302. 
39. Gomes AC, Barata JMS, Rochae Silva EO, Galati EAB: Aspectos ecológicos da leishmaniose tegumentar americana. 6. Fauna flebotomínea de matas residuais situadas na região centro-nordeste do Estado de São Paulo. Rev Inst Med Trop S Paulo 1989, 31(1):32-39.

40. Marcondes CB, Santos-Neto LG, Lozovei AL: Ecology of phlebotomine sandflies (Diptera, Psychodidae) in Brazilian Atlantic Forest. Rev Soc Bras Med Trop 2001, 34(3):255-260.

41. Brandão-Filho SP, Brito MEF, Carvalho FG, Ishikawa E, Cupolilo E, Floeter Winter LM, Shaw JJ: Wild and synanthropic hosts of Leishmania (Viannia) braziliensis in the endemic cutaneous leishmaniasis locality of Amaraji, Pernambuco State, Brazil. Trans R Soc Trop Med Hyg 2003, 97:291-296.

42. Hanafi HA, El-Din e-SM, El-Hossary SS, Kaldas RM, Villinski JT, Furman BD, Fryauff DJ: Experimental acquisition, development, and transmission of Leishmania tropica by Phlebotornus duboscai. Acta Trop 2013, 125:37-42.

43. Schlein Y, Yuval B, Warburg A: Aggregation pheromone released from thepalps of feeding female Phlebotomus papatasi (Psychodidae). J Insect Physiol 1984, 30(2):153-156.

44. Kelly DW, Dye C: Pheromones, kairomones and aggregation dinamycs of the sandfly Lutzomyia longipalpis. Annimal Behaviour 1997, 53(4):721-731.

45. Marcondes CB: A redescription of Lutzomyia (Nyssomyia) intermedia (Lutz \& Neiva, 1912), and resurrection of L. neivai (Pinto, 1926) (Diptera, Psychodidae, Phlebotominae). Mem Inst Oswaldo Cruz 1996, 91:457-462.

46. Marcondes CB, Lozovei AL, Vilela JH: Distribuição geográfica de flebotomíneos do complexo Lutzomyia intermedia (Lutz \& Neiva, 1912) (Diptera, Psychodidae). Rev Soc Bras Med Trop 1998, 31:51-58.

47. Gomes AC, Rabello EX, Santos JLF, Galati EAB: Aspectos ecológicos da leishmaniose tegumentar americana. 3. Observações naturais sobre o ritmo diário de Psychodopygus intermedius em ambiente florestal e extraflorestal. Rev Saude Publica 1983, 17(1):23-30.

48. Falqueto A: Especificidade alimentar de flebotomíneos em duas áreas endêmicas de leishmaniose tegumentar no estado do Espírito Santo, PhD Thesis. Rio de Janeiro: Fundação Oswaldo Cruz; 1995

49. Rangel EF, Barbosa AF, Andrade CA, Souza NA, Wermelinger EF: Development of Leishmania (Viannia) braziliensis Vianna, 1911 in Lutzomyiaintermedia (Lutz \& Neiva, 1912) (Diptera: Psychodidae: Phlebotominae) under experimental conditions. Mem Inst Oswaldo Cruz 1992, 87:235-238.

50. Rangel EF, Travi BL, Barbosa AF, Montoya J: Development of Colombian isolates of Leishmania (Viannia) panamensis, L. (V.) guyanensis and L. (V.) braziliensis in the sandfly Lutzomyia intermedia (Lutz \& Neiva, 1912) under experimental conditions. Mem Inst Oswaldo Cruz 1993, 88:513-515.

51. Paiva BR, Secundino NFC, Pimenta PFP, Galati EAB, Andrade JT Jr, Malafronte RS: Padronização de condições para detecção de DNA de Leishmania spp. em flebotomíneos (Diptera, Psychodidae) pela reação em cadeia da polimerase. Cad Saúde Pública 2007, 23:87-94.

52. Silva AC, Gomes AC: Estudo da competência vetorial de Lutzomyia intermedia (Lutz \& Neiva, 1912) para Leishmania (Viannia) braziliensis, Vianna, 1911. Rev Soc Bras Med Trop 2001, 34:187-191.

53. Gomes AC, Rabello EX, Santos JLF, Galati EAB: Aspectos ecológicos da leishmaniose tegumentar americana. 2. Ecótopo artificial como abrigo de Psychodopygus intermedius e observações sobre alimentação e reprodução sobre influência de fatores físicos naturais. Rev Saude Publica 1982, 16:149-159.

54. Costa SM, Cechinel M, Bandeira V, Zannuncio JC, Lainson R, Rangel DF: Lutzomyia (Nyssomyia) whitmani s.l. (Antunes \& Coutinho 1939) (Diptera: Psychodidae: Phlebotominae): geographical distribution and the epidemiology of American cutaneous leishmaniasis in Brazil. A mini-review. MemInst Oswaldo Cruz 2007, 102:149-153.

55. Soares RP, Margonari C, Secundino NC, Macêdo ME, da Costa SM, Rangel EF, Pimenta PF, Turco SJ: Differential midgut attachment of Leishmania (Viannia) braziliensis in the sand flies Lutzomyia (Nyssomyia) whitmani and Lutzomyia (Nyssomyia) intermedia. J Biomed Biotechnol 2010, 2010:439174.

56. Alves CR, Côrtes LMC, Brazil RP: The vectorial potential of Lutzomyia (Nyssomyia) intermedia and Lutzomyia (N.) whitmani in the transmission of Leishmania (V.) braziliensis can also be related to proteins attaching. J Biomed Biotechnol 2010, 2010:827851.

57. Margonari C, Soares RP, Andrade-Filho JD, Xavier DC, Saraiva L, Fonseca AL, Silva RA, Oliveira ME, Borges EC, Sanguinette CC, Melo MN: Phlebotomine sand flies (Diptera: Psychodidae) and Leishmania infection in Gafanhoto Park, Divinópolis, Brazil. J MedEntomol 2010, 47(6):1212-1219.
58. Pita-Pereira D, Souza GD, Pereira TA, Zwetsch A, Britto C, Rangel EF: Lutzomyia (Pintomyia) fischeri (Diptera: Psychodidae: Phlebotominae), a probable vector of American cutaneous leishmaniasis: detection of natural infection by Leishmania (Viannia) DNA in specimens from the municipality of Porto Alegre (RS), Brazil, using multiplex PCR assay. Acta Trop 2011, 120:273-275.

59. Silva DA: Aspectos ecológicos da fauna flebotomínea (Diptera, Psychodidae) e suas implicações na epidemiologia das leishmanioses em Cotia, Estado de São Paulo, Brasil. São Paulo, dissertação de mestrado. Faculdade de Saúde Pública da USP: São Paulo; 2005

60. Azevedo ACR, Rangel EF, Costa ME, David J, Vasconcelos AW, Lopes UG: Natural infection of Lutzomyia (Nyssomyia) whitmani (Antunes \& Coutinho 1939) by Leishmania of the braziliensis complex in Baturité, Ceará State, Northeast Brazil. Mem Inst Oswaldo Cruz 1990, 85:251.

61. Queiroz RG, Vasconcelos IAB, Vasconcelos AW, Souza RN, David JR: NeW World phlebotomine sandflies as Hosts of Leishmania (V.) braziliensis in an Endemic Area for cutaneous leishmaniasis in Ceara State, Northeast Brazil, First International Symposium on Phlebotomine Sandflies, Rome, Volume 87. 1991.

62. Pita-Pereira D, Alvesa CR, Souzab MB, Brazil RP, Berthoc AL, Barbosa AF, Britto CC: Identification of naturally infected Lutzomyia intermedia and Lutzomyia migonei with Leishmania (Viannia) braziliensis in Rio de Janeiro (Brazil) revealed by a PCR multiplex non-isotopic hybridisation assay. Trans R Soc Trop Med 2005, 99:905-913.

63. Guimarães VCFV: Avaliação da infecção natural de flebotomíneos (Diptera: Psychodidae) por Leishmania spp. no Município de São Vicente Férrer,Pernambuco. In MsC Dissertation. Recife: Fundação Oswaldo Cruz, Centro de Pesquisas Aggeu Magalhães; 2011 [http://www.cpqam.fiocruz.br/ bibpdf/2011guimaraes-vcfv.pdf]

64. Michalsky EM, Fortes-Dias CL, Pimenta PFP, Secundino NFC, Dias ES: Assessment of PCR in the detection of Leishmania spp in experimentally infected individual phlebotomine sandflies (Diptera: Psychodidae: Phlebotominae). Rev Inst MedTrop S Paulo 2002, 44:255-259.

65. Paiva BR, Secundino NFC, Nascimento JC, Pimenta PFP, Galati EAB, Andrade Junior HF, Malafronte RS: Detection and identification of Leishmania species in field-captured phlebotomine sandflies based on mini-exon gene PCR. Acta Trop 2006, 99:252-259.

66. Savani ESMM, Nunes VLB, Galati EAB, Castilho TM, Zampieri RA, Floeter-Winter LM: The finding of Lutzomyia almerioi and Lutzomyia longipalpis naturally infected by Leishmania spp. in a cutaneous and canine visceral leishmaniases focus in Serra da Bodoquena, Brazil. Vet Parasitol 2009, 160:18-24.

67. Saraiva L, Andrade Filho JD, Silva SO, Andrade ASR, Melo MN: The molecular detection of different Leishmania species within sand flies from a cutaneous and visceral leishmaniasis sympatric area in Southeastern Brazil. Mem Inst Oswaldo Cruz 2010, 105(8):1033-1039.

doi:10.1186/1756-3305-7-139

Cite this article as: Diniz et al:: Host-biting rate and susceptibility of some suspected vectors to Leishmania braziliensis. Parasites \& Vectors 2014 7:139.

\section{Submit your next manuscript to BioMed Central and take full advantage of:}

- Convenient online submission

- Thorough peer review

- No space constraints or color figure charges

- Immediate publication on acceptance

- Inclusion in PubMed, CAS, Scopus and Google Scholar

- Research which is freely available for redistribution 